\title{
An Inexpensive Disease Screening Technique for Foliar Blight of Chile Pepper Seedlings
}

\author{
Tito P. Alcantara ${ }^{1}$ and Paul W. Bosland ${ }^{2}$ \\ Department of Agronomy and Horticulture, Box 30003, New Mexico State \\ University, Las Cruces, NM 88003-0003
}

Additional index words. Phytophthora capsici, Capsicum annuum, disease resistance, plant breeding

\begin{abstract}
An inexpensive, rapid, and reliable seedling screening technique was developed to identify sources of resistance to foliar blight of Capsicum annuum $\mathrm{L}$. caused by the fungal pathogen Phytophthora capsici Leon. Leaf surfaces of test plants were inoculated with 500 to 1000 zoospores prepared in distilled water. Seedlings were incubated for 5 days in an easy-to-construct dew chamber and observed for symptom development. 'Criollo de Morelos 334' chile seedlings, a Mexican land race resistant to root rot caused by the same fungal pathogen, were highly resistant to foliar blight. All commercial cultivars tested in this study, however, were highly susceptible. No root rot symptoms were observed in any of the foliar-inoculated plants.
\end{abstract}

Chile is an important crop, nutritionally and economically (Bosland, 1992). Foliar blight, caused by the soilborne fungus Phytophthora capsici (Leonian, 1922), is a serious international disease problem of chile. This pathogen also causes root rot in chile. Foliar blight starts with a small circular or irregular-shaped lesion on the leaves giving a "scalded" appearance. Later, the lesions enlarge, dry, and bleach to a light tan. The disease progresses to the stem as a dark-green and water-soaked lesion. Finally, the plants are defoliated and stems dry and brown (Weber, 1932). In contrast, phytophthora root rot starts at the roots and progresses upward through the stem.

Splashing water due to heavy rainfall or overhead irrigation may allow normally soilborne $P$. capsici to infect aerial plant parts (Black et al., 1991). The disease may also result from sporangia and zoospores produced on diseased plant parts when environmental conditions are favorable. In recent years, foliar blight has become a serious problem in the warm, dry climate of New Mexico. It is usually observed during harvest time, August to October. Pathogen inoculation and infection occur when contaminated soils come in contact with wet leaves. Fruit pickers may also be responsible for disseminating the disease, especially when they harvest early in the morning when dew is still present on the leaf surface.

Received for publication 6 Dec. 1993. Accepted for publication 4 June 1994. A contribution of the New Mexico Agricultural Experiment Station, New Mexico State Univ., Las Cruces. The cost of publishing this paper was defrayed in part by the payment of page charges. Under postal regulations, this paper therefore must be hereby marked advertisement solely to indicate this fact.

${ }^{1}$ Graduate Research Assistant.

${ }^{2}$ Professor.
No commercial chile cultivars claim foliar blight resistance. This may be partly due to the unavailability of a reliable disease screening procedure. A precise inoculation method is important for evaluation of resistance to foliar blight under controlled environmental conditions. Infection of the main stem and roots had been a problem in previous inoculation techniques (Bosland, unpublished data) because plants die due to root rotting before foliar blight symptoms develop. In such cases, it is extremely difficult to determine whether plants are truly susceptible to foliar blight. This paper reports the development of an inexpensive, rapid, and efficient disease screening procedure for foliar blight of chile seedlings using zoospores as the inoculum.

\section{Materials and Methods}

Test plants. Seeds of 'Criollo de Morelos 334', strongly resistant to $P$. capsici, and four commercial cultivars, 'NuMex R Naky', 'NuMex Sweet', 'Jalapeño M', and 'Keystone Resistant Giant \#3', were sown in 3.9 $2.7 \times 5.5$-cm compartments of a 12 -cell pack plant container filled with a commercially prepared peatmoss-vermiculite mix (Greenhouse Supply, Albuquerque, N.M.) and placed on a heated plant propagation pad in the greenhouse to facilitate seed germination. The air inside the greenhouse had a diurnal range of 15 to $28 \mathrm{C}$. The trays were watered twice daily, and three to four beads of a slowrelease complete fertilizer $(14 \mathrm{~N}-6.2 \mathrm{P}-11.6 \mathrm{~K})$ were placed on the surface of each cell after seedling emergence.

Inoculum and incubation. Inoculum was prepared using the procedure described by Bosland and Lindsey (1991). Inoculum concentration was adjusted to 5000 zoospores $/ \mathrm{ml}$ using a hemacytometer. Six-week-old seedlings were inoculated by placing 100 to $200 \mu \mathrm{l}$ of inoculum on a partially expanded leaf using a micropipette. Noninoculated 'NuMex R Naky' was used as the control. The trays containing the seedlings were placed inside a $3 \times 1.25 \times 0.80-\mathrm{m}$, quonset-shaped mist chamber. The mist chamber consisted of a 6-mmthick polyethylene plastic tunnel constructed on a greenhouse bench (Fig. 1). The openmesh bench top was also covered with the plastic. A home-use humidifier, placed inside the chamber, provided a relative humidity of $70 \%$ to $100 \%$. Consequently, the foliage was wet throughout the incubation. The temperature inside the chamber had a diurnal range of 18 to 43C. Daytime light intensity was 1200 $\mu \mathrm{mol} \cdot \mathrm{m}^{-2} \cdot \mathrm{s}^{-1}$, and supplemental flourescent light was provided at night. The trays were rotated inside the chamber 3 days after inoculation to ensure uniform conditions.

Disease assessment. A completely randomized design experiment with three replications was used. Three seedlings per genotype per replication were inoculated as described. The plants were observed for symptom development 5 days after inoculation and observed daily until the infected plants defoliated. The following scale was used to score infected plants: $0=$ no symptoms; 1 through 3 $=$ small necrotic lesions through $<10 \%$ of total leaf area covered with scalded or light-tan lesions; 4 through $9=$ greater than or equal to $10 \%$ total leaf area with lesions through defoliated. Plants scored between 0 and 3 were considered resistant, and plants rated 4 through 9 were considered susceptible.

\section{Results}

The screening technique we used allowed the differentiation between susceptible and resistant plants. All of the commercial cultivars tested were similarly susceptible to foliar blight under the conditions used in this study. Scalding and light-tan lesions were observed on all fully expanded leaves of susceptible plants. Typical blight symptoms characterized by the sudden death of tissues were more pronounced in young leaves. The disease progressed to the petioles and main stem, causing defoliation. All aerial parts of the plant were blighted 10 days after inoculation. 'Criollo de Morelos 334' was highly resistant to foliar blight. No symptoms were observed on leaves or stems of this accession. Statistical analysis was not performed because all of the susceptible plants had the same score of 9 , and all of the resistant 'Criollo de Morelos 334' plants had a score of 1 .

The disease developed rapidly under the conditions used in this study. Leaf wetness is a prerequisite for infection (Schlub, 1983). The air was saturated inside the chamber throughout the incubation period, and dew formed on the leaves. Although the temperature fluctuated inside the chamber, an air maximum of $43 \mathrm{C}$ did not prevent infection and disease development. The use of a micropipette to place the inoculum on the leaves reduced the chance of zoospores coming in contact with the soil and eventually the roots. As a result, root rot symptoms were absent in infected plants. 


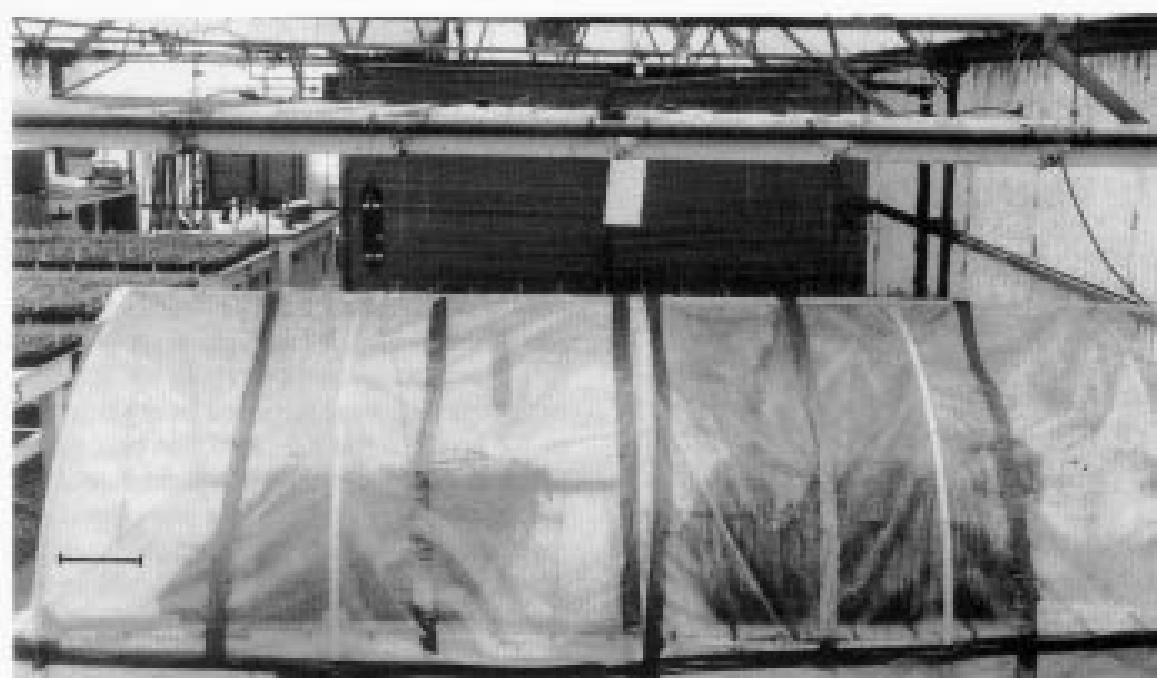

Fig. 1. Polyethylene plastic incubation chamber constructed on a greenhouse bench for screening phytophthora foliar blight of chile pepper $(\mathrm{bar}=20 \mathrm{~cm})$.

\section{Discussion}

The qualitative response of 'Criollo de Morelos 334' to foliar blight is not surprising because other researchers have reported that 'Criollo de Morelos 334' has high levels of resistance to phytophthora root rot (Bosland and Lindsey, 1991; Hartman and Wang, 1992; Reifschneider et al., 1992). With P. capsici, the use of zoospore suspension has proven to be a more effective inoculum than mycelial preparation (Reifschneider et al., 1986). In addition, zoospore suspension is easier and faster to prepare than oospore and sporangial suspensions. The inoculum concentration of 5000 zoospores $/ \mathrm{ml}$ used in this experiment was based on a commonly used dosage (Ansani and Matsouka, 1983; Reifschneider et al., 1986). This concentration was sufficient to detect differences between genetically resistant and susceptible plants. However, differ- ences in host response might be observed if a range of inoculum levels was used.

The incubation chamber technique used in this study is inexpensive and allows the plant breeder to screen at the seedling stage, thereby providing work continuity. This technique is more rapid than that described by Bowers and Mitchell (1991) because host predisposition and dark incubation are not necessary to obtain reliable results.

Success in breeding for disease resistance depends on the accuracy and precision of the disease screening technique used to identify sources of resistance. A reliable screening procedure allows for accurate differentiation of resistant germplasm from susceptible germplasm. Bosland and Lindsey (1991) had developed a seedling screening technique for root rot resistance. Together with the technique developed in this study, it is now possible to screen chile accessions for root rot and foliar blight sequentially or simultaneously at the seedling stage. This technique causes foliar blight, but does not induce the root rot phase of the disease. The technique described in this report for screening foliar blight can be used for inheritance studies of foliar blight resistance. Thus, investigations of the genetic mechanisms of resistance to both phases of the disease can now be performed.

\section{Literature Cited}

Ansani, C. and K. Matsouka. 1983. Sobrevivencia de Phytophthora capsici no solo. Fitopatologia Brasileira 8:269-276.

Black, L.L., S.K. Green, G.L. Hartman, and J.M Poulos. 1991. Pepper diseases: A field guide. Asian Veg. Res. \& Dev. Ctr., Shanhua, Taiwan.

Bosland, P.W. 1992. Chiles: A diverse crop. HortTechnology 2:6-10.

Bosland, P.W. and D. Lindsey. 1991. A seedling screen for Phytophthora root rot of pepper, Capsicum annuum. Plant Dis. 75:1048-1050.

Bowers, J.H. and D.J. Mitchell. 1991. Relationships between inoculum level of Phytophthora capsici and mortality of pepper. Phytopathology 81:178184.

Hartman, G.L. and T.C. Wang. 1992. Phytophthora blight of pepper: Screening for disease resistance. Trop. Pest Mgt. 38:319-322.

Leonian, L.H. 1922. Stem and fruit blight of peppers caused by Phytophthora capsici. Phytopathology 12:401-408.

Reifschneider, F.J.B., L.S. Boiteaux, P.T. Della Vecchia, J. Poulos, and N. Kuroda. 1992. Inheritance of adult-plant resistance to Phytophthora capsici. Euphytica 62:45-50.

Reifschneider, F.J.B., A.C. Cafe-Filho, and A.M. Rego. 1986. Factors affecting expression of resistance in pepper (Capsicum annuum) to blight caused by Phytophthora capsici in screening trials. Plant Pathol. 35:451-456.

Schlub, R.L. 1983. Epidemiology of Phytophthora capsici on bell pepper. J. Agr. Sci. 100:7-11.

Weber, G. 1932. Blight of peppers in Florida caused by Phytophthora capsici. Phytopathology 27:775-780. 